\title{
DIAGRAM KONTROL MULTIVARIAT SHORT PRODUCTION RUN UNTUK MEMANTAU MEAN DAN VARIABILITAS PROSES
}

\author{
Fathur Rahman $^{(1)}$, Muhammad Mashuri ${ }^{(2)}$ \\ (1),(2)Jurusan Statistika Fakultas Matematika Dan Ilmu Pengetahuan Alam, \\ Institut Teknologi sepuluh November Surabaya \\ Email: ${ }^{(1)}$ faturdocument@gmail.com ${ }^{(2)} \underline{\mathrm{m} \_ \text {mashuri@statistika.its.ac.id }}$
}

\begin{abstract}
ABSTRAK
Metode statistik proses kontrol untuk memantau proses jangka pendek (short-run) dengan mempertimbangkan pengukuran multivariat, atau metode diagram kontrol yang terbilang baru ini bisa juga disebut, diagram kontrol multivariat jangka pendek (short-run control chart) untuk memantau proses mean dan variabilitas. Untuk memantau mean proses pada diagram kontrol digunakan fungsi pengaruh mean dan matriks kovarian yang di harapkan dapat mendeteksi pergeseran kecil, dan untuk mengetahui pergeseran pada variabilitas proses maka digunakan komponen utama dan eigenvalue sebagai pengaruh fungsi. Teknik yang digunakan bersifat umum, dan pengaruh fungsi dapat digunakan untuk membangun diagram kontrol multivariat jangka pendek (short-run) baik untuk nominal vaule atau estimasi. Metode ini lebih lanjut diterapkan pada data pembuatan pipa bawah laut yang di produksi PT.KHI (Krakatau Hoogeven International) pada periode 2014. Hasil dari penelitian menujukan pergerseran variabilitas proses dan mean proses tidak dapat di deteksi dengan diagram kontrol kovensional, tetapi pergeseran mean dan variabilitas proses dapat di deteksi pada diagram kontrol yang menggunakan fungsi pengaruh mean dan matriks kovarian untuk medeteksi prorses mean, dan pengaruh fungsi komponen utama dan eigenvaluve untuk medeteksi variabilitas proses.
\end{abstract}

Kata kunci : Eigenvalue, pengaruh fungsi, statistik proses kontrol, komponen utama.

\section{PENDAHULUAN}

Statistik proses kontrol (SPC) merupakan suatu metode untuk mengendalikan kualitas yang dapat memberikan gambaran tentang proses yang sedang berjalan dengan mengambil sample untuk dianalisa dengan menggunakan teknik statistik, sehingga variabilitas dalam proses dapat dikurangi, Metode yang sering digunakan untuk mengetahui sumber variasi dari proses adalah Diagram Kontrol (Control Chart) beserta Analisis Kapabilitas Proses (Process Capability Analysis). Control Chart pertama kali dikenalkan oleh Dr. Walter Andrew Shewart dari Bell Telephone Laboratories Amerika Serikat pada tahun 1924.(Montgomery, D. C., 2005) (Bower, K. M., n.d.) (Prins, J., 2006) Pada umumnya diagram kontrol terbagi menjadi dua yaitu diagram kontrol univariate dan multivariate.

diagram kontrol multivariat standar adalah teknik yang telah diterapkan secara efektif pada sejumlah proses pengukuran produksi dalam jumlah kecil maupun besar, Seiring perkembangannya peningkatan perubahan produksi dari satu item ke item yang lain lebih sering terjadi pada perusahaan manufacturing baik dari skala kecil maupun skala besar, pada proses produksi dengan spesifikasi khusus biasanya subuah item yang di produksi sangat sedikit dan tidak kontinu, dengan kata lain proses produksi yang dilakukan berjalan singkat atau short production run._Salah satu bidang manufaktur dengan tingkat fleksibilitas yang tinggi adalah proses pembuatan pipa baja yang diproduksi oleh PT. KHI (Krakatau Hoogeven International) dimana pipa yang di buat menggunakan spesifikasi khusus dan diproduksi dalam dalam jumlah yang sedikit, dalam ruang lingkup produksi jangka pendek (short run production) biasanya sulit atau mungkin mustahil untuk mengumpulkan data yang diperlukan, untuk menerapkan teknik multivariat SPC klasik, karena produksi yang berjalan biasanya pendek atau cepat dan sering berubah dari satu bagian ke bagian lain.

Dalam proses multivariat, ketika penyebab khusus hadir, maka mereka dapat mempengaruhi parameter proses yang berbeda: mean proses, atau variabilitas proses, dan orientasi proses. Selanjutnya dalam tulisan ini peneliti akan membahas konsep diagram control multivariate untuk (short production run) dalam memantau mean dan variabilitas proeses

Fathur Rahman ${ }^{1}$, Muhammad Mashuri ${ }^{2}$ / J Statistika Vol. 9, No. 1 (2016) 
yang didasarkan pada statistik $T^{2}$ Hotelling untuk memantau mean proses dari fungsi pengaruh matriks covarians dan fungsi pengaruh dari eigen value untuk memantau variabilitas proses(L.Jaupi \& Gibert Saporta, 1997)(Luan Jaupi, 2002)(Chui Hengjian \& Chan Laikow, 2007)(C.P.Quesenberry, 2001), dan menerapkan konsep tersebut pada proses produksi pipe API5L-X65 oleh PT.KHI (PT. Krakatau Hoogovens International), dimana variabel pengukuran yang akan di gunakan dalam penelitian ini adalah Socket External Diameter, Barel External Diameter, Barel Internal Diameter, Overall lengeth.

\section{METODE PENELITIAN}

\section{Sumber Data}

Data yang digunakan dalam penelitian ini adalah data skunder yang di peroleh dari PT. KHI (PT. Krakatau Hoogovens International) yang berupa data dari proses produksi pipe API5L-X65, dimana variabel pengukuran yang akan di gunakan dalam penelitian ini adalah Socket External Diameter, Barel External Diameter, Barel Internal Diameter, Overall lengeth., periode 11 - 17 April 2014.

\section{Metode Penelitian}

Sesuai dengan tujuan penelitian ini maka langkahlangkah yang dilakukan terdiri dari dua bagian, yang diuraikan sebagai berikut:

1. Mendeskripsikan konsep diagram control multivariate untuk proses short run dengan memantau proses mean dan varians

2. Penerapan diagram control multivariat short production run untuk proses produksi sameles pipe API5L-X65 dengan memantau mean dan varians proses

a. Menghitung batas kontrol untuk data awal dimana masing-masing batas kontrol yang digunakan adalah $3 \sigma$ :

$$
\begin{aligned}
& U C L=\bar{X}+3 * \hat{\sigma} \\
& L C L=\bar{X}-3 * \hat{\sigma}
\end{aligned}
$$

pada tahap ini data yang digunakan untuk menghitung batas kontrol adalah data mentah yang diambil pada proses awal pengambilan sampel.

b. Memplot diagram kontrol short run pada data awal dengan acuan batas kontrol yang telah ditetapkan sebelumnya.

c. Menghitung batas kontrol untuk diagram kontrol $T^{2}$, dengan mengikuti distribusi $F$ dimana batas kontrol yang digunakan adalah:

$$
U C L=\frac{(n-1) p}{(n-p)} F \quad a, p, n-p
$$

d. Menghitung dan memplot diagram kontrol yang didasarkan pada statistik $T^{2}$ untuk proses mean dengan mengunakan variabel asli

$$
T_{i}^{2}=\left(x_{i}-\bar{x}\right)^{t} \hat{\Sigma}^{-1}\left(x_{i}-\bar{x}\right)
$$

kemudian dari masing-masing proses akan dibandingan dengan $T^{2}$ berbasis fungsi pengaruh dengan batas kontrol yang sama.

3. Membangun diagram kontrol short run berbasis fungsi pengaruh pada variabilitas proses.

a. Hitung rata-rata vektor $x_{i}$ dengan

$$
\bar{x}=\frac{\sum_{i=1}^{n} x_{i}}{n}
$$

b. Menghitung $C i j^{2}$ komponen utama dan matrik kovarians dari variabel $x_{i}$ dan $x_{j}$ :

$$
C_{i j}=\frac{1}{n} \sum_{p=1}^{n}\left(x_{i}^{(p)}-\bar{x}_{i}\right)\left(x_{j}^{(p)}-\bar{x}_{j}\right)
$$

c. Menghitung eigenvalue $\lambda$ pada dan eigen vektor $a$

$$
\begin{aligned}
& {[\lambda I-C]=0} \\
& \text { dan } \\
& {[\lambda I-C] a=0}
\end{aligned}
$$

d. Menghitung fungsi pengaruh komponen utama dan eigenvalue dengan persamaan

$$
\operatorname{IF}\left(x_{i}, \lambda_{j}, \widehat{F}\right)=C_{i j}^{2}-\hat{\lambda}_{j}
$$

Dimana $C i j^{2}$ adalah komponen utama dari $i^{\text {th }}$ observasi daneigen value $\hat{\lambda}_{j}$

e. Menentukan batas kontrol untuk data lanjutan dimana masing-masing variabel adalah bentuk data baru hasil tranformasi dari fungsi pengaruh komponen utama dan eigenvalue:

$$
\begin{aligned}
& U C L=\bar{X}+3 * \hat{\sigma} \\
& L C L=\bar{X}-3 * \hat{\sigma}
\end{aligned}
$$

Memplot diagram kontrol short run pada data lanjutan yang telah ditransformasi menggunakan fungsi pengaruh untuk variabilitas proses, dengan memplot masing-masing variabel yang kemudian hasil dari proses ploting akan dibandingkan dengan melihat kinerja dari masing masing-diagram kontrol.

\section{HASIL DAN PEMBAHASAN}

Penerapan Diagram Kontrol Short run Pada Proses Produksi Pipa Baja

penerapan diagram kontrol multivariate short production run untuk memantau means dan variabilitas proses, yang meliputi diagram kontrol yang didasarkan pada statistik $T^{2}$ dengan menggunakan fungsi pengaruh mean dari vektor Y yang digunakan untuk memantau mean proses, dan 
fungsi pengaruh eigenvalue pada komponen utama $j^{\text {th }}$ dari $i^{\text {th }}$ observasi digunakan untuk memantau variansi proses, dengan mengaplikasikan diagram kontrol short run pada data proses produksi pipa baja PT.KHI (PT. Krakatau Hoogovens International).

Tabel.1 Batas kontrol dengan mengunakan fungsi pengaruh dari eigenvalue

\begin{tabular}{lllll}
\hline $\mathrm{IF}(\mathrm{xi}, \lambda \mathrm{i}, \widehat{\mathrm{F}})$ Variance Proses & UCL & LCL \\
\hline & $3.886 \pm 3$ & $*$ & & - \\
$\mathrm{IF}(\mathrm{x} 1, \lambda 1, \widehat{\mathrm{F}}):$ & 11.1563 & & 37.35501 & 29.5833 \\
\hline & $3.928 \pm 3$ & $*$ & & - \\
$\mathrm{IF}(\mathrm{x} 2, \lambda 2, \widehat{\mathrm{F}}):$ & 8.1686 & & 28.43367 & 20.5784 \\
\hline & $3.973 \pm 3$ & $*$ & & - \\
$\mathrm{IF}(\mathrm{x} 3, \lambda 3, \widehat{\mathrm{F}}):$ & 7.9477 & & 27.81564 & 19.8706 \\
\hline & $3.983 \pm 3$ & $*$ & & - \\
$\mathrm{IF}(\mathrm{x} 4, \lambda 4, \widehat{\mathrm{F}}):$ & 3.7142 & & 15.12579 & 7.15949 \\
\hline
\end{tabular}

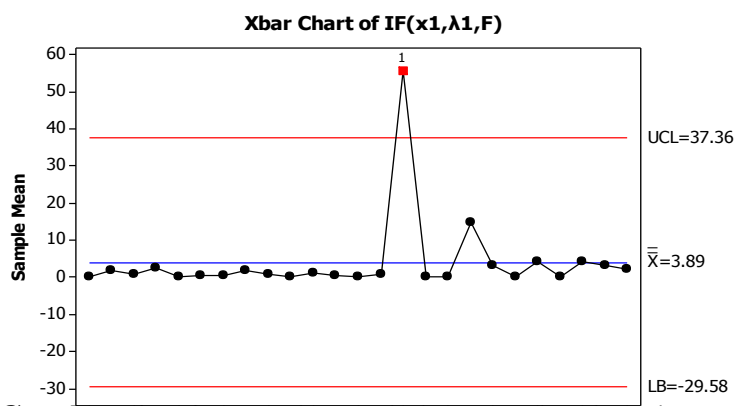

Gambar 3. ゆiagram kontrolishơrt runzeriasarkan fungsi pengorervasi eigen value pertama
Gambar 3. Diagram kontrol short run berdasarkan fungsi pengaruh eigen value ketiga.

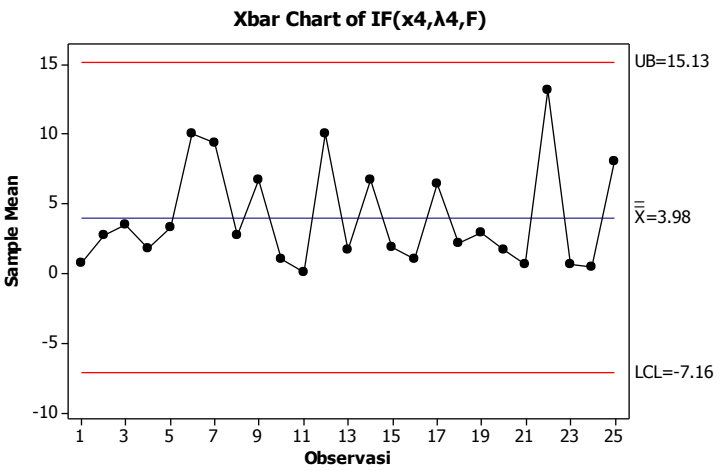

Gambar 4. Diagram kontrol short run berdasarkan fungsi pengaruh eigen value keempat.

Untuk mean proses diguanakan batas kontrol yang didasarkan pada statistik $T^{2}$ diamna batas kontrolnya adalah:

$$
\begin{aligned}
& U C L=\frac{(n-1) p}{(n-p)} F_{a, p, n-p} \\
& =\frac{(25-1) 4}{25-4} F 0.05,421 \\
& =12.58
\end{aligned}
$$

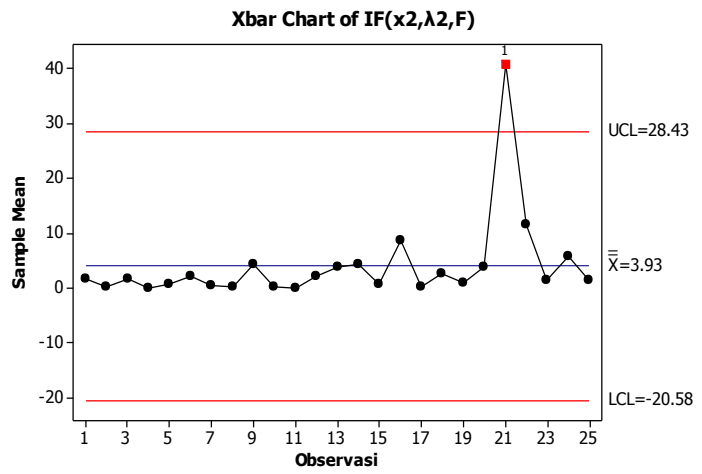

Gambar 2. Diagram kontrol short run berdasarkan fungsi pengaruh eigen value kedua

Xbar Chart of $\operatorname{IF}(\mathbf{x} 3, \mathbf{\lambda} 3, \mathrm{~F})$

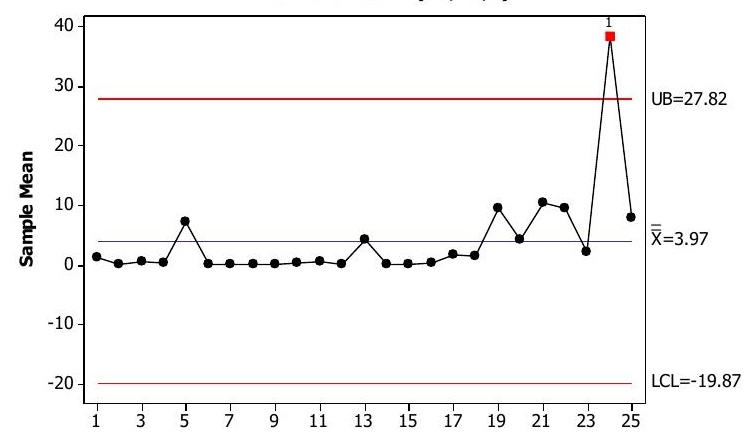

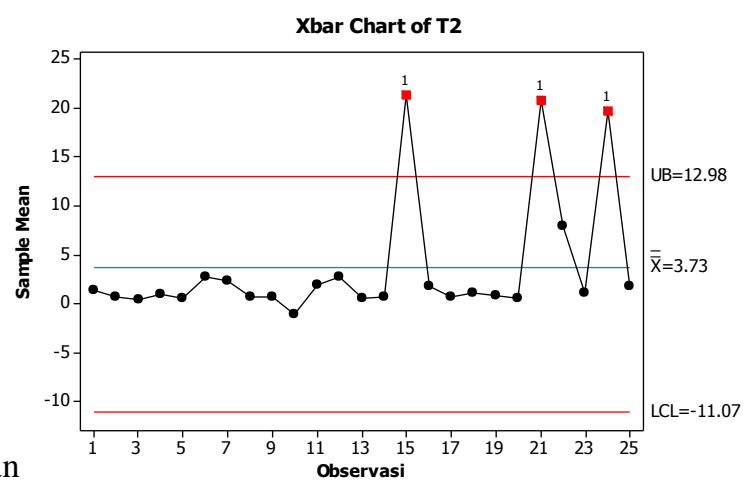

Gambar 5. Diagram kontrol short run berdasarkan fungsi pengaruh mean proses yang didasarkan pada statistik $\mathrm{T}^{2}$.

istika Vol. 9, No. 1 (2016) 


\section{KESIMPULAN DAN SARAN}

\section{Kesimpulan}

Diagram kontrol dengan menggunakan fungsi pengaruh dari eigenvalue efektif di gunakan untuk mendeteksi pergeseran kecil pada proses dimana ditunjukan pergeseran varians pada observasi ke 15, 20 dan 24 pada gambar 1,2 dan 3. Dan diagram kontrol yang di dasarkan pada statistik $T^{2}$ dengan menggunakan fungsi pengaruh dapat mendeteksi tiga pergeseran pada proses secara bersamaan yaitu pada observasi ke 15, 20 dan 24 dimana diman di tunjukan pada gambar 5. Sehingga dapat disimpulkan masing-masing diagram kontrol fungsi pengaruh untuk proses mean dan varians dapat digunakan untuk proses short procution run.

\section{Saran}

1. Diagram konrol dengan menggunakan fungsi pengaruh yang didasarkan pada statistik $T^{2}$ atau distribusi $\chi^{2}$ akan efisien jika jumlah karakteristik kualitas tidak lebih besar dari empat. Jika jumlah karakteristik kualitas lebih besar dari empat maka hanya pergeseran besar dapat dideteksi dengan menggunakan diagram kontrol ini. Oleh karena itu untuk proses dengan jumlah data yang besar, maka pengurangan variabel asli harus di pertimbangakan, sehingga variabel yang berperan penting saja yang di ambil.

2. Diagram kontrol dengan menggunakan fungsi pengaruh dapat diterapkan pada hampir semua situasi pada kasus real, sehingga untuk pengembangan selanjutnya fungsi pengaruh dapat di gunakan untuk mengatur Diagram kontrol dengan batas kontrol probabilistik yang ditetapkan berdasarkan distribusi dari statistik yang digunakan untuk memantau proses dan jenis kesalahan pertama pada fase I. Dan diagram kontrol CUSUM untuk data terukur serta untuk atribut.

\section{DAFTAR PUSTAKA}

Montgomery, D. C. (2005). Introduction to statistical quality control.(5th ed.). Hoboken, New Jersey: John Wiley \& Sons, Inc.

Bower, K. M. (n.d.).Statistical process control $(S P C)$. Retrieved from http://asq.org/learnabout-quality/statistical-processcontrol/overview/overview.html

Prins, J. (2006). Proportions control charts. In NIST \& SEMATECH (Eds.), e-Handbook of Statistical Methods (chap. 6.3.3.2). Retrieved from http://www.itl.nist.gov/div898/handbook/

L.Jaupi \& Gibert Saporta (1997). Control Chart for Multivariate Process Based on Influence Function, Confrence on Statistical Science, Verlag basel.

Luan Jaupi (2002). Multivariate Control Chart For Complex process, Multivariate Total Quality Control, A Springer-Verlag Company.

Chui Hengjian \& Chan Laikow (2007), Control Chart For Short Run, Chinese Journal of Applied Probability and statistics, Vol 23 No 2.

C.P.Quesenberry.(2001). The Multivariate Short Run Snapshot Q Chart. Quality Engineering, Vol. 13 No. 4, pp. 679-683. 